\title{
Article \\ Mindful application of digitalization for sustainable development: The Digitainability Assessment Framework
}

\author{
Shivam Gupta ${ }^{1 *}$ (1) , Jakob Rhyner ${ }^{1}$ (1) \\ 1 Bonn Alliance for Sustainability Research, University of Bonn \\ * Correspondence: shivam.gupta@uni-bonn.de
}

Version February 3, 2022

\begin{abstract}
Digitalization is widely recognized as a transformative power for sustainable development. Careful alignment of progress made by digitalization with the globally acknowledged Sustainable Development Goals (SDGs) is crucial for inclusive and holistic sustainable development in the digital era. However, limited reference has been made in SDGs about harnessing the opportunities offered by digitalization capabilities. Moreover, research on inhibiting or enabling effects of digitalization considering its multi-faceted interlinkages with the SDGs and their targets is fragmented. There are only limited instances in the literature examining and categorizing the impact of digitalization on sustainable development. To overcome this gap, this paper introduces a new Digitainability Assessment Framework (DAF) for context-aware practical assessment of the impact of the digitalization intervention on the SDGs. The DAF facilitates in-depth assessment of the many diverse technical, social, ethical, and environmental aspects of a digital intervention by systematically examining its impact on the SDG indicators. Our approach draws on and adapts concepts of the Theory of Change (ToC). The DAF should support developers, users as well policymakers by providing a 360-degree perspective on the impact of digital services or products, as well as providing hints for its possible improvement. We demonstrate the application of the DAF with the three test case studies illustrating how it supports in providing a holistic view of the relation between digitalization and SDGs.
\end{abstract}

Keywords: Digitalization; Sustainable digitalization; Artificial Intelligence; Sustainable Development; SDGs; Assessment Framework; Mindful; Digital Age; Digitainability

\section{Introduction}

The UN Agenda 2030 [1] calls for inclusive action towards sustainable development, covering a broad spectrum of areas ranging from poverty eradication and universal health protection to environmental conservation and peacebuilding. The 17 Sustainable Development Goals (SDGs) and their respective targets, along with particular indicators, require timely monitoring and reporting of the progress in member states of the UN. The frame of 232 indicators developed by the Inter-Agency Expert Group (IAEG) helps measure progress towards the achievement of the SDGs. Accelerating progress towards SDGs is urgently required, augmenting the need for data-driven systemic and context-inclusive approaches to nudge on-ground development. An influential role is played by digitalization, and particularly artificial intelligence (AI) [2]. As Tegmark [3] puts it, "the more intelligent and powerful machines get, the more important it becomes that their goals are aligned with ours", which in our context would rather be the SDGs. Digitalization encapsulates the individual, organizational, and societal transformation triggered by mass adoption of algorithm and data-driven 
interventions that generate, process, and transfer information [4-6], drawing from a very diverse set of methodologies and technologies $[7,8]$. It is essential to explore in detail whether and to what extent the opportunities offered by the digitalization interventions (DIs) can be aligned with mindfulness for sustainable development upon particular attention to the achievement of the goals mentioned in the 2030 Agenda [9].

With mindful use of digitalization, we are referring to the capability to be aware of where we are in the digitalization development process and how we plan to utilize it further, considering it in a comprehensive sustainability context. This protects us from being overwhelmed by uncritical optimism on the one hand or by systematic pessimism on the other hand, but rather be more rooted in the explicit contexts for sustainable development. To find the context-driven on-ground function of technology for SDG at the target or indicator level, it is essential that we explicitly comprehend why it is used, what problem it is addressing, who is responsible for action, when is it that the DI offers the desired results and how is it working in reality. The debate about the benefits and risks of utilizing digitalization to support progress towards sustainability has started but remains fragmented [10,11]. Numerous entanglements and contexts remain poorly understood, thus demanding further research towards the mindful use of digitalization.

Several studies indicated that the DIs collect and utilize diverse amounts of resources, which might not necessarily benefit SDGs as a whole [10-12]. Trade-offs concerning social and environmental sustainability are discussed more broadly [13]. Various frameworks and analytical methods were developed to assess the acceptance and applications of technologies in specific domains and contexts. These tools, qualitative as well as quantitative, can be utilized for predicting the usefulness of technologies across industries and development areas [14]. There also exist some modified versions of the frameworks as mentioned earlier to assess the usability of the technologies under particular conditions incorporating broader sustainability contexts [15]. However, these frameworks are fragmented in their approach to analyzing in isolation considering certain SDG(s) and are domain-specific, thus limiting the understanding of the impacts digitalization offers for SDGs and their indicators $[10,12]$. This fragmented understanding may lead to an ill-defined prioritization, eroding the holistic aspiration and enactment of the Agenda 2030. In order to transition from the present fragmented knowledge to more holistic evidence about the impact of digitalization for SDGs, the paper introduces the Digitainability Assessment Framework (DAF), which maps the impact of a DI on SDG indicators. The inclusive framework garners information about a DI, contexts, process, outcome to reflect the overall impact on the SDGs. The SDG indicator framework [16] offers an internationally agreed structure for the assessment of the sustainability of the DI. Realizing what follows when the DI is brought to practice, e.g., intervention or service is "rolled out" with stakeholders, is vital to address implementation challenges and align it for the advancement of the SDGs. The alignment of the DI with SDGs renders a more sustainable DI [17]. The DAF should help to guide this alignment.

This paper is organized as follows. In Section 2, three essential dimensions are discussed that need to be taken into account in a comprehensive assessment of the sustainability of the DIs (digitainability assessment), namely synergies and trade-offs between the SDGs, the context dependency, and the stakeholder structures. Taking into account these considerations, Section 3 introduces the DAF. The paper then presents the results obtained by the operationalization of the DAF for three test case studies on the diverse DIs in Section 4, namely spatial optimization for the systematic deployment of citizen-driven air quality monitoring networks, blockchain for healthcare service delivery, and remote sensing-based machine learning approaches for disaster risk management and planning. Finally, the discussion concerning considerations and limitations are presented in Section 5, followed by the conclusions and outlook in Section 6.

\section{Critical dimensions for a digitainability assessment}

Digitalization is generally regarded as an essential element for driving sustainable transformations [18]. There has been rapid adoption of digital technologies as a versatile, complex, and powerful 
resource capable of performing specific tasks requiring a vast amount of human capacity [19]. Despite several constraints in different circumstances, there is a growing moment in leveraging the DI for addressing matters related to the SDGs and their targets [20]. A couple of recent studies focused on charting the contribution of the DI for monitoring SDGs indicators within stand-alone "for good" projects in a particular domain [21,22], rather than to also identify the counterproductive effects of digitalization capacities for bridging the 2030 Agenda complicated challenges [20]. Only a limited effort was devoted to exploring the relationship between the DI and SDGs as a whole [23].

When assessing the impact of the DI for sustainability, we cannot treat it as a tool or process acting independently of its environment. In this section, we will discuss three specific dimensions, which a comprehensive assessment always needs to consider. First, the intrinsic complexity of the SDG framework with its synergies, but also trade-offs, needs to be taken into account. The DI may support certain indicators while simultaneously being at odds with others. The second one is the context dependency. A given DI may have a different impact in industrialized and in non-industrialized context. The third one is the stakeholder structure. Depending on the intentions and preferences of the stakeholders (providers, users, etc.), the DI may work out differently. In the following, these three essential dimensions are considered in more detail.

\subsection{Synergies and Trade-offs between SDGs}

In order to make progress in SDGs, it is crucial to acknowledge the dynamic relations between the indicators of the goals in terms of their potential interactions, both across and within each SDGs $[24,25]$. Progress will significantly depend on utilizing the synergies while addressing the potential trade-offs. Adshead et al. [26] pointed out that the infrastructure intended for delivering SDGs, as well as the potential trade-offs between indicators, are important dimensions to be considered when making investment and policy intervention decisions, asserting the findings of Schroeder et al. [27], especially in the context of the environment, society, and human health.

There is extensive research exploring synergies and trade-offs between SDGs [28-33]. In particular, Pradhan et al. [34] explored the synergies and trade-offs between SDGs indicators in 227 countries, classifying the goals considering their interactions; however, the interactions are identified based on the correlation among indicator level data, not implying causality. Scherer et al. [35] investigated the interactions between SDGs 1, 6, 10,13, and 15, arguing that social goals usually lead to increase environmental impacts. Mainali et al. [36] explored interaction amid the SDGs 1,2,6 and 7 in South Asia and Sub-Saharan Africa context, suggesting that potential synergies and trade-offs among the SDGs vary depending on multiple aspects such as geographical conditions, infrastructure, and the policy measures. Nerini et al. [30] measured the water-energy-food nexus (SDG 2,6,12), identifying tensions concerning SDG 7 (for example, energy access), and stressed the need for careful planning of complex energy systems underpinning long term development processes. von Stechow et al. [37] investigated the trade-offs between Climate Action (SDG13) and the rest of SDGs, suggesting that curbing energy demand is crucial across the goals. However, the characterization of how digitalization influences SDG interactions is not well documented yet. Consideration about the interface between social, ethical, environmental and technical effects of the DI also needs to be understood while approaching sustainability, particularly considering the rebound effects, as already pointed out by Jevons in 1865 when addressing paradoxically increased consumption and offset savings [38]. Nishant et al. [39] also discussed the increase in total consumption of limited resources, even when considering environmentally effective systems.

Thus, it is crucial to understand the cascading impacts caused by digitalization over already discussed trade-offs like negative digital and ecological footprint, environmental impacts, climate crisis, pollution, social tensions, and inequalities together with non-resilient and fragmented practices towards sustainability [40-42]. It is essential to uncover how spillover effects and indirect impacts hinder the realization of several SDGs in long/short terms [43], which might not be obvious when 
taking action. To address these concerns, contextual awareness is a crucial dimension [44-46]. The research mentioned above builds an important basis for the DAF to be introduced in the paper.

\subsection{Context Dependency}

To understand the impact of the DIs, the awareness of the context is essential for striking the right balance between protecting the essential dimension of sustainability and implementing practices fostering holistic, sustainable development. As an example, the impact of innovative technologies and data sources such as satellite images in the context of climate change may have lesser ethical risks than compared to other data sources and domains such as in healthcare and public safety domain, where personal data plays a crucial role [47]. Also, the impact of technologies in developed countries vs. developing or low-income countries varies in their level of adoption, local governance priorities, level of acceptance, energy demands, culture, infrastructure, and other particular local aspects [36]. Digitalization might be helpful to amplify scientific discovery and governance towards shedding light on the multifaceted SDGs interlinkages, and their cascading impacts [48-50].

Extant studies do not yet provide or add up to a systematic mapping of the impact of digitalization on SDGs. The relevance of context to demonstrate how or why the specific DI outcomes can be realized and how it might lead to certain synergy and tradeoffs between other targets/indicators of SDGs or limit the generalizability of intervention to different settings or circumstances is fundamental. A DI facilitates us in what we aim to achieve, whereas the context accounts for the specific outcomes [51,52]. The relevance of the context in using the DIs for particular objectives is usually reflected with the help of theories, frameworks, and taxonomies that are useful in exploring the inhibiting and enabling aspects of various potential outcomes [53]. In the literature, methods such as Theory of Change (ToC) [54], and Theory of Acceptance (ToA) [55] seem to cover context as one of determinants. Terms such as "context," "setup," and "environment" were often used synonymously in the reference of technology implementation and related domains [56]. The context-aware assessment about the role of a DI for SDG indicators with the capability to acknowledge the complexities of the SDGs has yet to be developed $[57,58]$, highlighting the need for systemic and context-aware approaches to utilize digitalization mindfully for SDG progress.

\subsection{Multi-stakeholder structure}

Understanding the complex role digitalization can have on the interaction of SDGs, and the context that frames the role it can have for the SDGs will require multi-stakeholder involvement to systematically exploit the DIs for the progress of the SDGs and beyond. Measuring timely progress on how well the intervention satisfies the key stakeholders of their requirements is vital [59]. A lack of integrated and collective approaches leads to SDG implementation being isolated projects with little or no impact [60]. It is crucial that sustainable development being prioritized and seen as a core value, where trust-building was considered necessary [61]. Krellenberg et al. [62] stress that the SDGs suffer from insufficient ambition and that they compete or overlap with other local context-driven actions. Köhler et al. [63] highlighted the role of the DIs, and policy alone could not facilitate easy transformations to sustainability. Further elements such as coherent strategy, enablers, regulation, competencies are required [64]. Socio-technical aspects linked to hindrance in a DI adoption, widening digital divide, lack of trust in machine-driven approaches need to be revisited in the specific contexts for sustainable development with the DIs [40]. To identify further the potential enablers, the role of grassroots and civil society is critical but explored sparsely [65].

Insights concerning the DIs acceptance and creating public awareness for initiating collective actions towards SDGs are also little [66]. Consideration of social factors such as local context, reluctance in technology application, and awareness is crucial for inclusive action [41]. Recent literature recognizes the relevance of encouraging multi-stakeholders participation and collaboration among key actors to support pathways of sustainable development with digitalization [67-69]. However, the unclear roles and responsibilities and silo-based inertia lead to a lack of integrity in the implementation process 
for SDGs [68,70]. Existing implementation practices are limited in the transformative power and strategic abilities [60], which hinders the overall implication of digitalization for SDGs. Literature also stresses the lack of tools and guides for reporting and imbalanced alignment among corporate strategies, policies, and scientific outlook, leading to counterproductive outcomes for digitalization and sustainable development [71,72]. The available literature, although still fragmented, shows the importance of the consideration of the stakeholder structure in the assessment.

The synergy and trade-off interrelations between the SDGs, the context dependency, and the stakeholder structure form three critical dimensions for a thorough assessment of the impact of digitalization on sustainable development. Fortunately, as shown in this section, a considerable body of research is already available. It will put us in a position to formulate the Digitainability Assessment Framework (DAF) in the next section.

\section{Digitainability Assessment Framework (DAF)}

The central idea of the DAF is to systematically examine the impact of a DI on the indicators underpinning the SDGs. In doing so, the DAF draws from and adapts concepts of Theory of Change (ToC), which represent a mapping of causal pathways between changes that have taken place and the activities the transformation processes undertake, track changes, and demonstrate impacts [73,74]. It is important to mention at this point that the ToC is referring to the impact on ("change" for) the SDG indicators and not on possible improvements ("change") of the DI. In this sense, the scope of the DAF is primarily an assessment of the impact of DI on sustainable development and not on the improvement of the DI. While the assessment often may give valuable hints for improvement, its systematic investigation and realization are beyond the scope of the DAF.

The ToC as an approach in itself is not a unique defined theory but rather a set of rules allowing for goal-oriented planning, suitable for identifying and simplifying the complexity, reflecting on the enabling and inhibitory potential change process brought by the DIs. ToC concepts are widely recognized as a practice-oriented approach and is not a fixed methodology. It allows flexibility to work according to the needs. However, there are consensus about the basic elements that constitute ToC (discussed in the following section). Application of ToC as a methodology has been successfully used for testing and validation of two long-standing areas: program theories and development practices [75]. Considering the flexibility ToC offers to different circumstances and adaptable to the different contexts, we believe ToC could guide the assessment of DI considering the planning and implementation activities. Therefore, in the DAF, we are embedding ToC elements to combine practitioner's perspectives not for the evaluation/improvement of DI in itself but rather for the assessment of the impact of the DI on SDGs with the scientifically-backed evidence [76,77].Recently, $\mathrm{Li}$ and Thomas [78] also proposed the application of Theory of Change (ToC) as a methodology and a process to measure the impact of ICT technologies; however, their focus was not on sustainable development.

Typically, the ToC approach is composed of five key parts - Inputs, Activities, Outputs, Outcomes and Impact [79]. They allow for a combination of quantitative and qualitative criteria for the explanation of the change process [80], and could capture multiple aspects of change, including social, governance, and security perspectives [81]. In applying ToC, appropriate boundaries, scope, and level of complexity are essential [82]. We adapt the ToC concept with a specific focus on the SDGs and a DI for the DAF development. Notably, the adaptations are made to capture the ways how the causal linkages are considered between the role of DI and SDG indicators anticipating the particular context and impact types. The adaptations made in the DAF also help capture the multi-level changes brought by a DI, which could be mapped - as the "impact pathway" - presenting each impact in logical connection to all the relevant SDG indicators and the plausible convergence of crucial information.

We map the ToC parts into the DAF segments, as follows:

- Digitalization Intervention (containing ToC parts Input and Activities) 


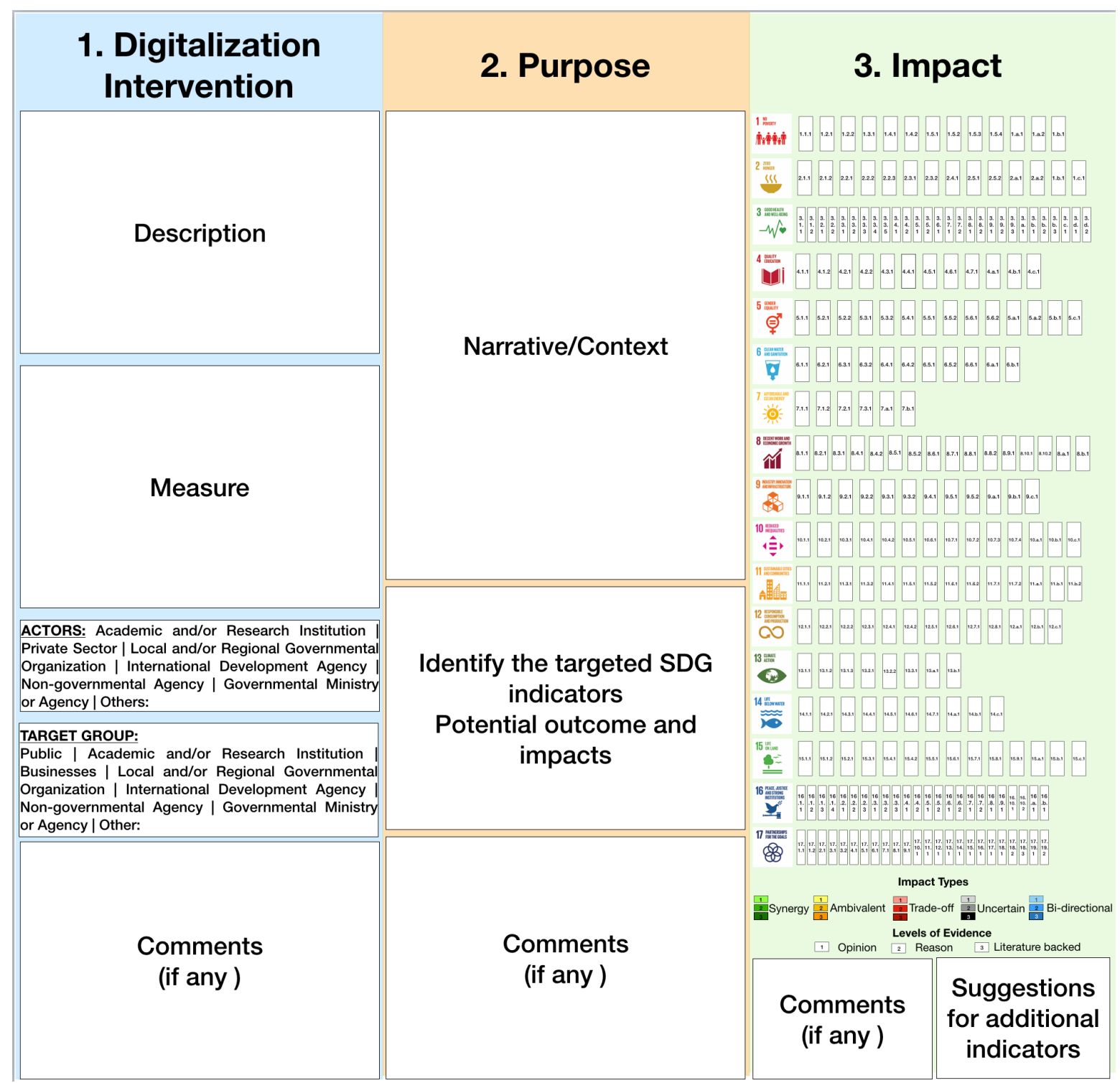

Figure 1. Digitainability Assessment Framework (DAF) overview

- Purpose (Outputs and Outcomes)

- Impact (including desired as well as undesired impact)

The three DAF segments are described in detail in the following subsections. When executed together in sequential order, they allow for determining the relevance and impact of a DI on SDGs at the indicator level. Figure 1 illustrates the structure of the DAF. In the following subsections, each segment and associated elements are described.

\subsection{Digitalization Intervention}

The first segment of the DAF requires context-based information about a DI under consideration. It contains the following elements:
(a) Description,
(b) Measure,
(c) Actors,
(d) Target group,
(e) Comments. 
The first four elements capture the basic description of the intervention, measure it will focus, along with the owner or primary actor of the intervention, and finally the target group which a DI is serving, respectively. The fifth element of the segment (Comments) provides scope to integrate information that might be relevant and not covered in the preceding elements. Overall, the Digitalization intervention segment aims to gain the necessary information required to answer the questions:

1. What is a DI taken by the actor to bring change in the context of the SDGs?

2. What is the context within which the intervention is taking place?

3. Who are the initiators, and who are the intended receivers (e.g., governmental body, industry, NGO, international organization, public)?

\subsection{Purpose}

In the second segment of the DAF, information concerning;

(a) Narrative: defines the intended outcome from the DI,

(b) Envisaged SDG targets and indicators.

(c) Comments

While the first element contains a narrative with some context about the intended effects of the intervention, the second element maps the narrative into the SDG targets and indicator framework [16]. As in the previous segment, the third element provides scope to integrate information that might be relevant and not covered in the preceding elements. Overall, the Purpose segment aims to gain the necessary information required to answer the questions:

1. What is the purpose of the DI (narrative)?

2. What are the targeted SDG indicators to be influenced by the DI?

\subsection{Impact}

This segment seeks information about the eventual impact of the DI beyond the envisaged Purpose (Segment 2). In the Impact segment, the user examines all the SDG indicators and evaluates the impact of the DI with respect to the indicator. We define the Impact types described below. Furthermore, for the assignment, we define three possible Levels of Evidence to back the claim. They are also defined below. Figure 2 represents the different Impact Type required to be backed with the Level of Evidence for particular impact type claimed. In the cases where the user feels that the existing SDGs targets and indicators are not specific enough to cover any specific aspect important for fostering sustainable development or lacking a systematized measure of progress considering the DI and SDGs, the comment section and the additional indicator suggestion section in the Impact segment provides the opportunity in the DAF to incorporate these vital information considering specific context and end outcomes.

\section{Impact Type}

To incorporate the types of impact identified by the user for each SDG indicator, in the DAF, we classified Impact types into the following five categories:

(a) Synergy: implies that the DI impacts an SDG indicator in a synergistic manner. For example, the DI supporting Indicator 9.c.1 (Proportion of population covered by a mobile network, by technology) is likely to have a synergistic impact on the Indicator 17.8.1 (Proportion of individuals using the Internet).

(b) Ambivalent: implies that the DI impacts an SDG indicator in both a synergistic and trade-off manner. For example, the impact of AI technology on indicator 9.4.1 (Carbon emission per unit of value-added): while AI itself is a heavy energy consumer, on the one hand, it could also support in reducing the energy consumption if used conscientiously in energy systems on the other hand. Often, the lack of verifiable information on the short- and projected medium-term impact is limited and suffers from a lack of systematic and accurate measurements [83]. 
(c) Trade-off: implies that while the DI under consideration directly advances particular indicator(s) might hinder the progress of other indicators of SDGs. For example, application of digitalization intervention for Indicator 3.8.1 (Coverage of essential health services) might lead to hindrances for Indicator 8.4.1 (Material footprint, material footprint per capita, and material footprint per GDP) or Indicator 7.3.1 (Energy intensity measured in terms of primary energy and GDP) because of increasing demand by digital infrastructure.

(d) Uncertain: implies that while the DI might lead to an impact on the indicator, it is not ascertainable how and when (in the long term) there might be an impact. This impact type is meant to cover the situations where the logical inferences direct confidence on a particular type of impact, but evidence and rationale are not well identified. The second reason for assigning an impact to this type is if there is disagreement on the impact. Example, blockchain-based DI with demand-benefit uncertainties associated with respect to energy and finance impacting various SDG indicators related to climate change, energy demand, financial inclusiveness, and sustainable consumption.

(e) Bi-directional: In contrast to the previous four impact types, which are unidirectional(impact of the DI on indicators of SDGs), the bidirectional impact aims to identify the bi-directional, i.e., they are not only impacting indicators, but reversely they are (also) impacted by indicators. For example, the DI in smart grid systems might have a bi-directional impact on Indicator 7.1.1 (Proportion of population with access to electricity). However, for practical reasons, we will make one restriction when identifying the purpose of the bi-directional impact type. We will typically not include overarching aspects such as those related to peace, although they are crucial for sustainable development and are bi-directional. Unless a DI is explicitly related to peace or conflict issues, the importance of peace-related indicators is often self-evident and to not add to the risk-benefit analysis of the intervention.

The aforementioned Impact types must be backed by confirmation in the DAF for a comprehensive assessment. Figure 2 illustrates the different Impact Types, with the numbers on the left representing different Levels of Evidence.

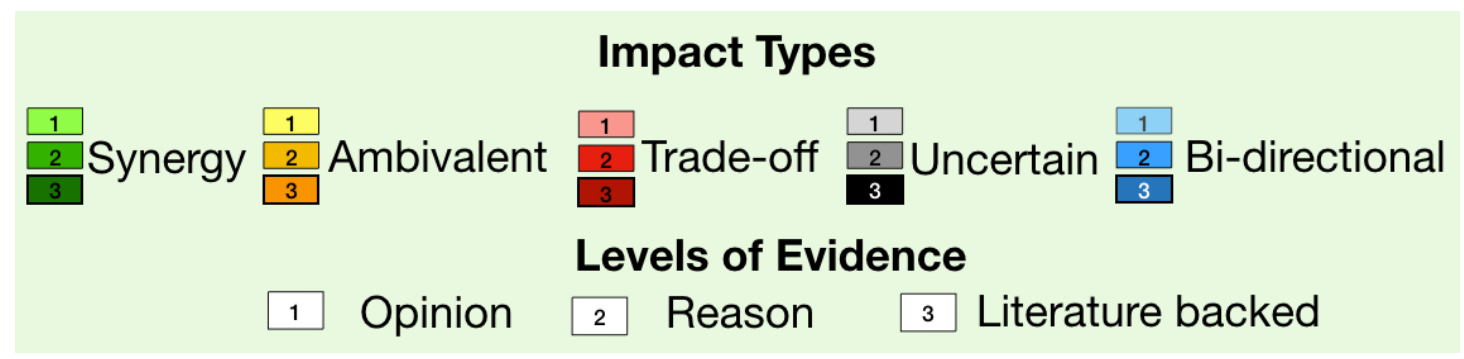

Figure 2. Legends of Impact Type required in the DAF backed with Levels of Evidence.

\section{Levels of Evidence}

We define three different Levels of Evidence to which impact on the indicators can be assessed, depending on the purpose for which the DAF is executed.

1. Opinion: refers to personal opinions or beliefs, based on personal knowledge, without detailed investigation. While this level does not yet necessarily provide valid evidence, it may provide the first mapping of opinions, perceptions, and assumptions as a starting point but also collect relevant indicators, e.g., in a discussion group or a poll.

2. Reason: refers to judgment with a justification and, where appropriate, a discussion of the underlying displaying assumptions. This may be a next step beyond the Opinion level in a discussion group.

3. Literature backed: refers to literature and data-backed evidence from research, or practitioner knowledge, published in accredited sources. 
It is encouraged that the user of the DAF provides evidence at Level 3 for legitimate inferences, but Levels 1 and 2 may represent useful precursor steps. Particularly, executing Level of Evidence 1 may reveal misperceptions. The DAF may also be used in an iterative way, refining reason and opinion based on expert level consideration of certain impacts. During the development process of the DAF, the elements of the DAF in each segment were nested or simplified to capture the most relevant information and minimize the number of inputs needed from the user. The refinement in the segments and their respective elements were based on multiple discussions between authors and reiterations to ensure that each element used in it enables the observation of critical aspects required to evaluate the impact of the DI for SDGs.

The information in the Impact segment helps in generating an impact profile that reflects on the following key questions:

1. What SDG indicator(s) are impacted by the DI? How?

2. How well is the DI aligned with the Agenda 2030?

3. What are the overall consequences of the DI for the SDGs as a whole, besides the intended outcome?

Inspecting the DI in a particular context requires scrutiny and in-depth evaluation of all SDGs indicators. Therefore, we encourage end-user to exercise the DAF in two phases;

- First Phase: identifying the relevant indicators, i.e., those indicators that logically be impacted by the DI.

- Second Phase: assessing the impact type for each indicator on the preferred levels of evidence.

To test the operationalization of the DAF, we use a custom-built excel sheet (Supplementary S1), which covers both phases. The procedure prescribed in the scheme help in executing the DAF step by step. In the following section, we demonstrate the operationalization of the DAF with the help of 3 test case studies.

\section{Results- Test case studies}

This section describes the results of the studies we have undertaken to show how to operationalize the DAF in three different test case studies on the different levels of evidence to elucidate the application of different categories of Impact Types and Levels of Evidence.

\subsection{DAF test case 1: Spatial optimization for systematic deployment of citizen-driven air quality monitoring networks}

According to $\mathrm{WHO}$, around $92 \%$ of the world's population lives in places where air quality levels exceed prescribed limits [84]. In the recent pandemic, exposure to air pollution was one of the significant contributors, leading to an increase in COVID-19 cases $[85,86]$. Generally, air pollution monitoring is performed by environmental or governmental organizations using a network of fixed monitoring stations. With the significant advancements in the DIs such as the Internet of Things (IoT), cloud computing, edge computing and machine learning, citizens and environmental agencies are exploring the potential of citizen-driven air quality monitoring initiatives to enable high spatial resolution and real-time data collection on air quality in the cities [87]. However, to better understand the high-resolution spatial variability in air pollution in cities, data accuracy profoundly depends on the location where the data is collected. Considering the importance of the topic to public health globally, we use the work conducted by Gupta et al. [88] as a test case to understand the potential implication of the intervention for the achievement of SDGs. The method defined in this study supports identifying the "optimal" location in the city of Münster (Germany) to place the optimal number of IoT devices for air quality monitoring in a systematic manner for sustainable use of citizen's effort and IoT devices for air quality monitoring at the city level. The DI could directly support the progress toward SDG indicators: 
- 3.9.1 Mortality rate attributed to household and ambient air pollution

- 11.6.2 Annual mean levels of fine particulate matter (e.g., PM2.5 and PM10) in cities (population weighted)

\begin{tabular}{|c|c|c|c|}
\hline $\begin{array}{l}\text { 1. Digitalization } \\
\text { Intervention }\end{array}$ & 2. Purpose & \multicolumn{2}{|c|}{ 3. Impact } \\
\hline \multirow[t]{2}{*}{$\begin{array}{l}\text { DESCRIPTION } \\
\text { Air pollution optimisation method to identify } \\
\text { the optimal location to place Internet of } \\
\text { Things (loT) sensors for air quality data } \\
\text { collection with precision considering the } \\
\text { scientifically backed method Land Use } \\
\text { Regression (LUR). }\end{array}$} & \multirow[t]{5}{*}{$\begin{array}{l}\text { NARRATIVE/CONTEXT } \\
\text { The method aims to solve the problem of } \\
\text { identifying optimal location to increase the } \\
\text { spatial distribution of air pollution monitoring } \\
\text { station to support air quality data collection. } \\
\text { In the proposed work, the method is deployed } \\
\text { in the developed country context and with } \\
\text { significant number of citizens participating in } \\
\text { the process. }\end{array}$} & \multirow{5}{*}{\multicolumn{2}{|c|}{ 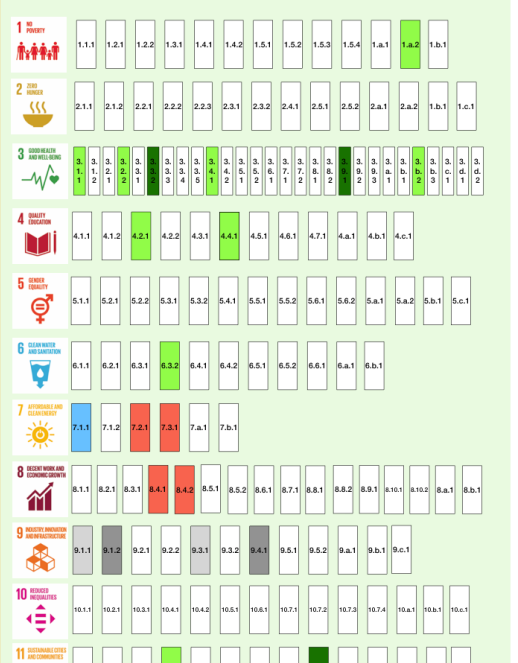 }} \\
\hline & & & \\
\hline \multirow{4}{*}{$\begin{array}{l}\text { MEASURES } \\
\text { The technology can help in systematically } \\
\text { placing optimal number of loT devices at } \\
\text { "crucial" locations with the helps of citizen } \\
\text { participation. }\end{array}$} & & & \\
\hline & & & \\
\hline & & & \\
\hline & \multirow{3}{*}{$\begin{array}{l}\text { TARGATED SDG INDICATORS } \\
\begin{array}{l}\text { Improved data collection support in progress } \\
\text { of Indicator } 3.9 .1, \text { Indicator } 11.6 .2 .\end{array}\end{array}$} & \multirow{4}{*}{\multicolumn{2}{|c|}{ 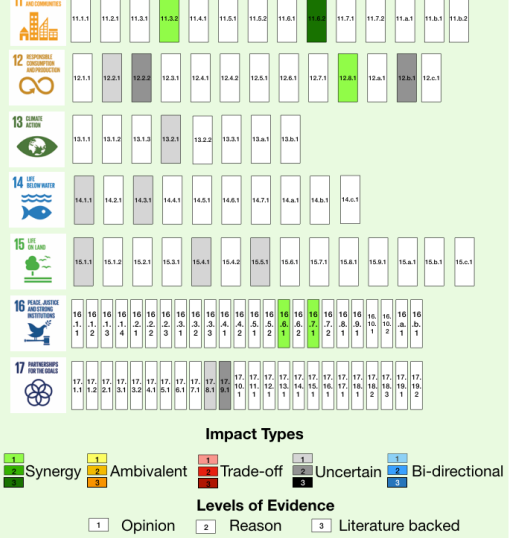 }} \\
\hline $\begin{array}{c}\text { ACTORS } \\
\text { Academic and/or Research Institution | } \\
\text { Private Sector | Local and/or Regional } \\
\text { Governmental Organisation }\end{array}$ & & & \\
\hline $\begin{array}{c}\text { TARGET GROUP } \\
\text { Citizens | City council | Private Companies }\end{array}$ & & & \\
\hline \multirow{2}{*}{ No additional comments } & \multirow[b]{2}{*}{ No additional comments } & & \\
\hline & & \begin{tabular}{|c|} 
COMMENTS \\
Issues concerning data \\
privacy when using loT \\
and data ownership is \\
not covered in the SDG.
\end{tabular} & $\begin{array}{l}\text { ADDITIONAL INDICATORS } \\
\text { Digital transformation } \\
\text { with privacy issue } \\
\text { consideration. }\end{array}$ \\
\hline
\end{tabular}

Figure 3. Filled DAF with all essential information concerning test case 1

When analyzing the impact of the optimization method and IoT deployment using the DAF, we found 14 synergies and 3 potential trade-offs. We have also identified 15 indicators that can be impacted, but these impacts are unclear yet and far-fetched (Level 1 Impact Type). Most of the Level 1 impact synergies between indicators are based on the relationship rooted in the application of data gathered after the optimization method is utilized. Impact was identified for indicators; 1.a.2 Proportion of total government spending on essential services (education, health, and social protection) for planning purposes [89], exposure assessment in the context of 3.1.1 Maternal mortality rate, 3.2.2 Neonatal mortality rate [90] and 3.3.2 Tuberculosis incidence per 100,000 population [91]. The indirect relation between air pollution and lifestyle-related disease in indicator 3.4.1 Mortality rate attributed to cardiovascular disease, cancer, diabetes or chronic respiratory disease [92]. Furthermore, increased access to high-resolution air quality data can empower medical research and health sectors, indicator (3.b.2) air pollution impacts development and growth in several forms [93]. Access to high-resolution data can decrease the impact 
of child physical and psychosocial development (4.2.1) along with the long-term impact on water bodies with ambient air quality (Indicator 6.3.2) [94,95]. The motive of the approach to also foster citizen participation in data collection enables many synergies, including indicator 11.3.2 Proportion of cities with direct participation structure of civil society in urban planning and management [96], supporting education for sustainable development (Indicator 12.8.1). Active involvement of citizens could lead to improved population satisfaction with their experience of public services (Indicator 16.6.2) and population who believe that decision-making is inclusive and responsive.

Table 1. The reference to publications where the Impact Type has been treated on Level of Evidence "Literature Backed" and the reasoning for Levels of Evidence "Reason" and "Opinion" for test case study 1 can be found in the supplementary material S2.

\begin{tabular}{||l||l||}
\hline \multicolumn{2}{||c||}{ DAF Test Case 1 } \\
\hline Impact Type & Indicators \\
\hline \hline Synergy & $1 . a .2[89], 3.1 .1[90], 3.2 .2[90], 3.3 .2[91], 3.4 .1[92], 3.9 .1[93]$, \\
& $3 . b .2[93], 4.2 .1,4.4 .1,6.3 .2[94,95], 11.3 .2[96], 11.6 .2[88]$, \\
& $12.8 .1,16.6 .1,16.7 .1$ \\
\hline Ambivalent & NA \\
\hline Trade-offs & $7.2 .1[97], 7.3 .1[97], 8.4 .1[98], 8.4 .2[98]$ \\
\hline Uncertain & $9.1 .1,9.1 .2,9.3 .1,9.4 .1,12.2 .1,12.2 .2,12 . b .1,13.2 .1,14.1 .1$, \\
& $14.3 .1,15.1 .2,15.4 .1,15.5 .1,17.8 .1,17.9 .1$ \\
\hline Bi-Directional & 7.1 .1 \\
\hline
\end{tabular}

Trade-offs were found with indicators linked to increased energy share in the total final energy consumption (Indicator 7.2.1) [97], impact on the energy intensity of primary energy and GDP (Indicator 7.3.1) [97], increase in material footprint (Indicator 8.4.1), and impact on domestic material consumption (Indicator 8.4.2) due to increasing demand of infrastructure for air quality data collection [98]. The bi-directional impact was also identified between Indicator 7.1.1 Proportion of population with access to electricity and the DIs. To install sensors for air quality measurement based on optimization method outcome, the population in the city needs to have access to electricity. The uncertain impacts include indicator 9.1.1 Proportion of the rural population who live within $2 \mathrm{~km}$ of an all-season road as the optimization method uses road information data for assessing air quality, 9.1.2 Passenger and freight volumes as transportation is one of the significant contributors of air pollution, 9.3.1 Proportion of small-scale industries in total industry value-added as the industry also contributes to the air pollution, 9.4.1 CO2 emission per unit of value-added may get impacted because of access to information about air quality burden it might create. Privacy issues are also not sufficiently covered by any of the SDG targets and associated indicators unless it leads to unjust and discriminatory outcomes and practices. We also identified the need for additional indicators to handle privacy and cybersecurity concerns while addressing sustainability with the DIs. Table 1 and Figure 3 summarize the results of test case 1 . More detailed information of impact assessment for each indicator and associated comments can be assessed from the supplementary file S2.

\subsection{DAF test case 2: Blockchain for healthcare service delivery}

Telehealth and telemedicine systems are supportive in remote healthcare services delivery, especially during the COVID-19 pandemic [99]. However, these systems are generally centralized and limited in providing necessary data security, integrity, transparency, preventing health records immutability, and traceability for fraud detection concerning insurance [100-102]. Blockchain is considered suitable for transactions with a limited digital footprint (decreased disclosure of sensitive digital data) alongside transparency and immutability [103] and thus can satisfy the requirements of telehealth and telemedicine service delivery. Considering the increasing attention given to the blockchain in health care, we analyze the DI within the DAF. 
The blockchain technology for healthcare delivery could help directly promote the progress towards SDG indicators:

- 3.8.1 Coverage of essential health services

- 3.b.1 Proportion of the target population covered by all vaccines included in their national programme

- 3.b.3 Proportion of health facilities that have a core set of relevant essential medicines available and affordable on a sustainable basis

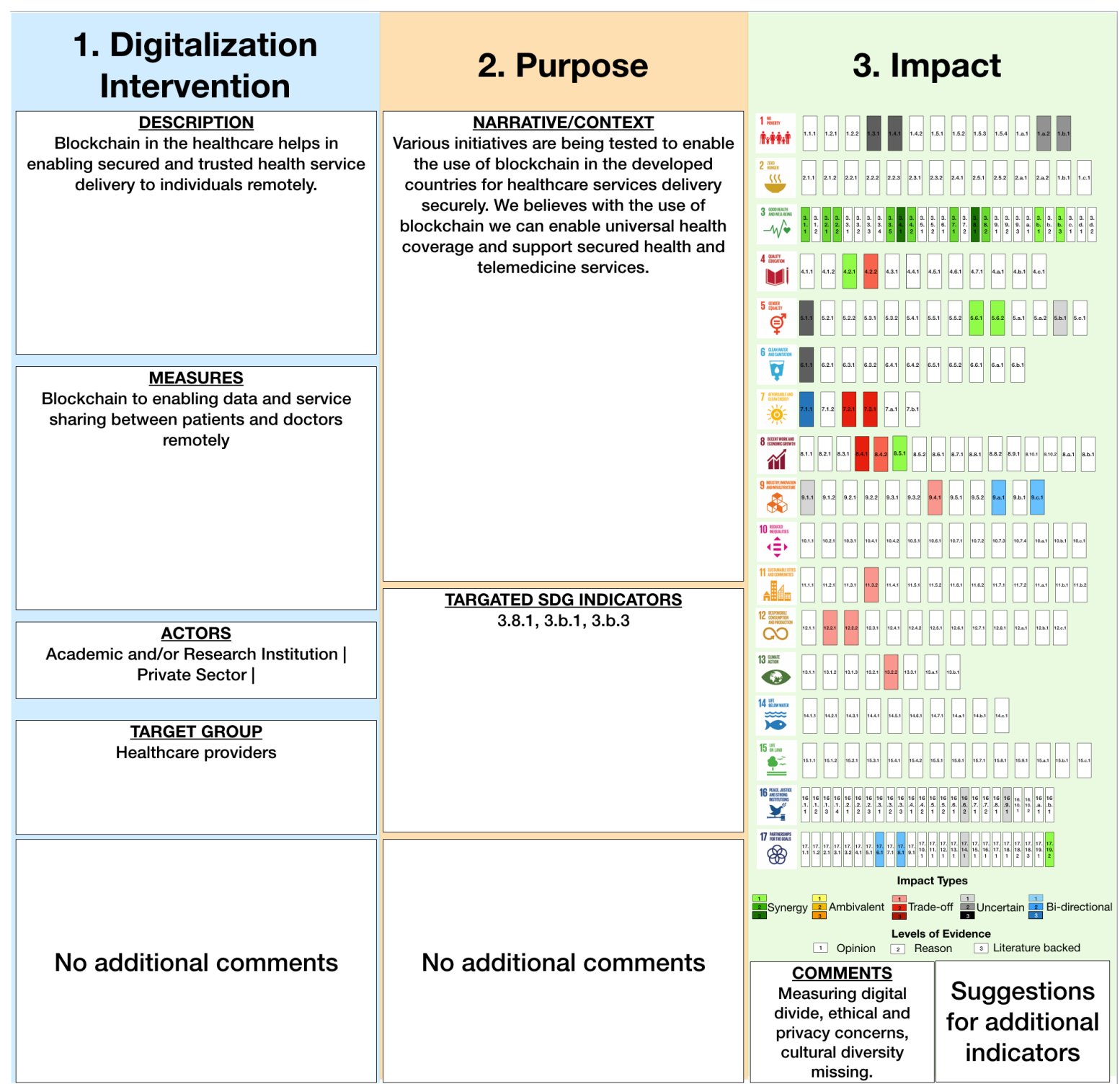

Figure 4. Filled DAF with all essential information concerning test case 2.

With the help of the DAF, we identify 16 possible synergies and 10 trade-offs. Five bi-directional and 11 uncertain impacts were further identified. Many of the synergies are attributed to increased access to the healthcare services and related infrastructure, such as increased access remotely in a privacy-preserving manner along with decreased digital footprint (by facilitating models that allow for minimal disclosure of sensitive digital data) can lead to decreasing 3.1.1 Maternal mortality ratio, 3.2.1 Under-5 mortality rate, 3.4.1 Mortality rate attributed to cardiovascular disease, cancer, diabetes or chronic respiratory disease and 3.4.2 Suicide mortality rate [104-107]. Increased trust in the system enabled by blockchain can also support in progressing 5.6.1 Proportion of women aged 15-49 years who make their own 
Table 2. The reference to publications where the Impact Type has been treated on Level of Evidence "Literature Backed" and the reasoning for Levels of Evidence "Reason" and "Opinion" for test case study 2 can be found in the supplementary material S3.

\begin{tabular}{||l||l||}
\hline \multicolumn{2}{||c||}{ DAF Test Case 2 } \\
\hline Impact Type & Indicators \\
\hline \hline Synergy & $3.1 .1[104], 3.2 .1[105], 3.4 .1[106], 3.4 .2[107], 5.6 .1,5.6 .2$, \\
& $8.5 .1,17.19 .1$ \\
\hline Ambivalent & NA \\
\hline Trade-offs & $7.2 .1[108], 7.3 .1[108], 12.2 .1[109], 12.2 .2[109]$ \\
\hline Uncertain & $1.3 .1,1.4 .1,1 . a .2,1 . b .1,5 . b .1,6.1 .1,16.6 .2,16.9 .1[110]$, \\
& 17.14 .1 \\
\hline Bi-Directional & $9 . a .1,17.6 .1,17.8 .1,7.1 .1$ \\
\hline
\end{tabular}

informed decisions regarding sexual relations, contraceptive use, and reproductive health care, 5.6.2 Number of countries with laws and regulations that guarantee full and equal access to women and men aged 15 years and older to sexual and reproductive health care, information and education, 8.5.1 Average hourly earnings of employees, by sex, age, occupation and persons with disabilities which can facilitate resources availability to strengthen statistical capacity in developing countries (17.19.1).

Likewise, possible trade-offs identified are related to the increased energy consumption (7.2.1, 7.3.1) and infrastructure requirements (12.2.1, 12.2.2) [108,109], resulting in environmental impacts (8.4.1, 8.4.2, 9.4.1, 13.2.2) and social impacts such as the digital divide (4.2.2). Further, the uncertain aspects mainly were identified for subsequent access to basic facilities and further resources other than healthcare (1.3.1,1.4.1,1.a.2,1.b.1, 5.b.1, 6.1.1,16.6.2,16.9.1) that the integrated approach of blockchain can empower [110]. The use of a blockchain system can not only support local-level healthcare access but can also boost the progress toward national and international cooperation and access to resources (17.14.1). Bi-directional impacts were linked to the available digital infrastructure (17.6.1,17.8.1,7.1.1), policy frameworks to utilize the technology appropriately (9.a.1). Figure 4 presents the overall DAF populated with impacts identified considering the specific application and context of blockchain as a technology for SDGs. As can be seen from the figure, the advantage of the blockchain to decrease the digital footprint comes with a trade-off of a large ecological footprint. We also identified the lack of indicators that can concretely cover the aspect of the digital divide, ethical concerns such as respect to traditional belief while using technologies, and respect to cultural diversity, as commented in the impact segment. The results are summarized in Table 2 and Figure 4. Additional information can be found in the supplementary file S3.

\subsection{DAF test case 3: Machine learning for analysis of Satellite-based images for disaster risk management}

Machine learning (ML) is a subset of artificial intelligence (AI), but the two terms are sometimes used interchangeably. ML algorithms are machine programs that learn to perform particular tasks using a specific form of data inputs and rule sets. Disaster risk management and planning system relies on many different data sources and types for modeling. The application of ML approaches, such as artificial neural networks (ANN), support vector machines (SVM) and random forest (RF), and different deep-learning convolution neural networks (CNNs) on satellite images for disaster risk management and planning is growing [111]. Regardless of the relevance of these methodological and technological advancements, little is known yet, about their potential to support the achievement of 2030-Agenda as a whole. To holistically scrutinize their impact, we have considered a test case of ML on satellite images for disaster risk management and planning to explore potential impacts on SDGs with the help of the DAF. The machine learning method for disaster risk management and planning aims to directly support the progress of: 
- 13.1.1/1.5.1 Number of deaths, missing persons and directly affected persons attributed to disasters per 100,000 population

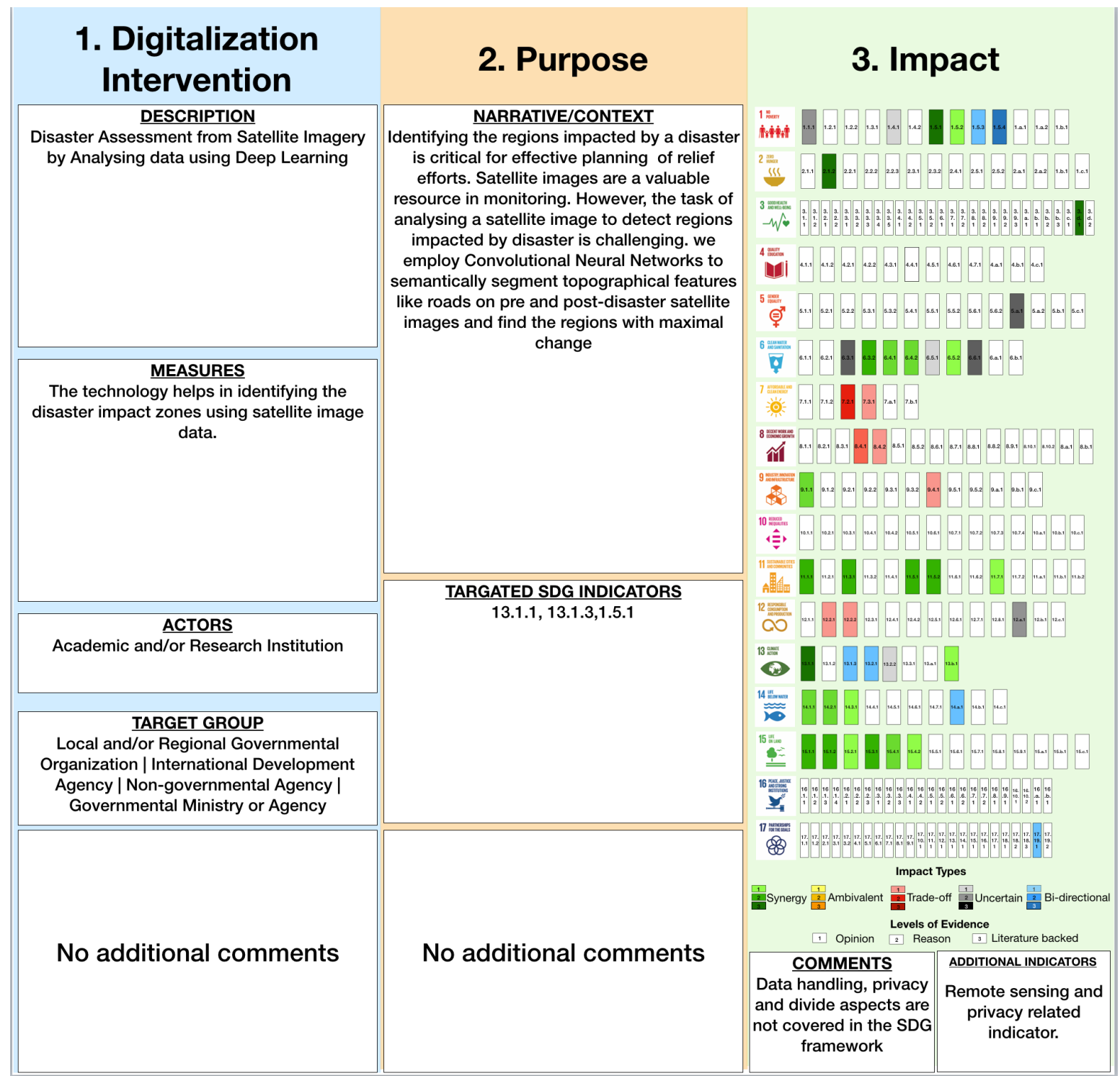

Figure 5. Filled DAF with all essential information concerning test case 3

While the ML approach directly supports the above-listed indicator, we identified possible 25 indicators with synergies and 7 trade-offs with the DAF procedure. Many of the synergies are based on the notion that the various environmental factors considered in the disaster planning and management processes can lead to benefits for environmental indicators. Satellite image analysis include identification of land use change, type and potential population at risk which could support in indicators: 2.1.2 Prevalence of moderate or severe food insecurity in the population, based on the Food Insecurity Experience Scale (FIES) [112], 6.3.2 Proportion of bodies of water with good ambient water quality, 6.4.2 Level of water stress: freshwater withdrawal as a proportion of available freshwater resources [113], 9.1.1 Proportion of the rural population who live within $2 \mathrm{~km}$ of an all-season road, 11.1.1 Proportion of urban population living in slums, informal settlements or inadequate housing [114], 11.3.1 Ratio of land consumption rate to population growth rate, 11.5.2 Direct economic loss in relation to global GDP, damage to critical infrastructure and number of disruptions to essential services, attributed to disasters, 11.7.1 Average share of the built-up area of cities that is open space for public use for all, by sex, age and persons with disabilities, 15.1.1 Forest area as a proportion of 
Table 3. The reference to publications where the Impact Type has been treated on Level of Evidence "Literature Backed" and the reasoning for Levels of Evidence "Reason" and "Opinion" for test case study 3 can be found in the supplementary material S4.

\begin{tabular}{||l||l||}
\hline \multicolumn{2}{||c||}{ DAF Test Case 3 } \\
\hline Impact Type & Indicators \\
\hline \hline Synergy & $2.1 .2[112], 6.3 .2[113], 6.4 .2[113], 9.1 .1,11.1 .1[114], 11.3 .1$, \\
& $11.5 .2,11.7 .1,15.1 .1,15.1 .2,15.2 .1,15.3 .1,15.4 .1$ \\
\hline Ambivalent & NA \\
\hline Trade-offs & $7.3 .1,8.4 .1 / 12.2 .1,8.4 .2 / 12.2 .2,9.4 .1[115]$ \\
\hline Uncertain & $1.1 .1,1.4 .1,5 . a .1,6.3 .1,6.5 .1,12 . a .1$ \\
\hline Bi-Directional & $13.1 .3,13.2 .1$, \\
\hline
\end{tabular}

total land area, 15.1.2 Proportion of important sites for terrestrial and freshwater biodiversity that are covered by protected areas, by ecosystem type, 15.2.1 Progress towards sustainable forest management, 15.3.1 Proportion of land that is degraded over total land area, 15.4.1 Coverage by protected areas of important sites for mountain biodiversity, altogether the advantages of the technology contribute in encouraging progress for 13.1.3 Proportion of local governments that adopt and implement local disaster risk reduction strategies in line with national disaster risk reduction strategies.

Significant trade-offs are identified with indicators 7.3.1 Energy intensity measured in terms of primary energy and GDP, 8.4.1/12.2.1 Material footprint, material footprint per capita, and material footprint per GDP, 8.4.2/12.2.2 Domestic material consumption, domestic material consumption per capita, and domestic material consumption per GDP, 9.4.1 CO2 emission per unit of value-added [115]. These trade-offs could be attributed to the energy demand and digital infrastructure required to train and implement the model. Uncertain impacts such as 1.1.1 Proportion of the population living below the international poverty line by sex, age, employment status and geographic location (urban/rural), 1.4.1 Proportion of population living in households with access to basic services, 5.a.1 (a) Proportion of total agricultural population with ownership or secure rights over agricultural land, by sex; and (b) share of women among owners or rights-bearers of agricultural land, by type of tenure, 6.3.1 Proportion of domestic and industrial wastewater flows safely treated, 6.5.1 Degree of integrated water resources management, 12.a.1 Installed renewable energy-generating capacity in developing countries (in watts per capita) could be benefited with the same technology if integrated processes are used in the long term. Bi-directional impacts on indicators such as, 13.1.3 Proportion of local governments that adopt and implement local disaster risk reduction strategies in line with national disaster risk reduction strategies, 13.2.1 Number of countries with nationally determined contributions, long-term strategies, national adaptation plans, and adaptation communications, as reported to the secretariat of the United Nations Framework Convention on Climate Change are identified based on mutual benefits it provided to each other for sustainable development. Concern regarding remote sensing based privacy breaches as well as data divide are also not significantly covered in SDGs but might be covered when such issues lead to a lack of justice and accountability. The outcome of this test case study also indicates the need for additional indicators to address privacy concerns related to DI, such as remote sensing. The additional indicator which considers the digital footprint and underlying anonymity measure (or digital security) could be useful. Table 3 and Figure 5 summarize the results; additional information can be found in the supplementary file $\mathrm{S} 4$.

The results of the 3 test case studies clearly demonstrate how the DAF adds value to our current knowledge on the DIs' impact on SDG. It helps to identify the potential diverse impacts of the DIs beyond the well-known synergies and trade-offs in SDGs. For the test study case 1, where the focus of DI is on indicators of target 3.9 and 11.6, Anderson et al. [116] reported synergies with targets 3.2, 3.3, 7.1, 15.1, 15.4, and 17.8, whereas trade-offs between indicators of 16.8, 10.6, 15.5 and target 11.6. Interestingly the DAF acknowledges all the above interactions but also identifies several interactions beyond what is reported in recent literature. Likewise, for the test case study 2, where the DI is targeted 
on the indicators of Target 3.8 and 3.b, Anderson et al. [116] reported trade-offs between target 3.b, 10.6 and 16.8 and synergy between $10.6,16.8$, and 15.5. Moreover, in test case study 3 , where the DI addresses Target 13.1 and 1.5, synergies are reported with 11.5.

Overall, the results of the test case studies demonstrate that not only does the DAF identify DI impacts within the well-known synergies and trade-offs amid SDGs, but it also goes beyond existing knowledge by identifying casual pathways of linkages with far more interactions that are yet to be explored. Consequently, the proposed framework extends our understanding of the impact of the DIs on sustainable development beyond the current status quo.

\section{Discussion}

This study proposed a context inclusive and actor specific framework for evaluating the practical impacts of the DIs and the cascading effect it may have on the synergy and trade-offs across the entire SDGs. The DAF approach is drawing from the Theory of Change (ToC) concepts. We adopted ToC schemes in the three DAF segments: Digitalization Intervention, Purpose, Impact. Each segment of the DAF is dedicated to capturing specific practical information supportive of concealing the crucial information about the DI's impact on SDGs, such as the actors involved, the target group, the context in which intervention is planned, the specific aim of the planned intervention, and the overall impact of intervention across all the SDG indicators. The exercise helps identify the role digitalization may have considering the multifaceted interlinks between SDG indicators that may appear due to a particular context while using a particular DI. The DAF then supports developing the impact profile of the DI considering all the SDG indicators. Anderson et al. [116] recently reported the systems model based on the outcomes of past systemic interactions among SDG indicators spatiotemporally (across countries and years aggregated) at the global level. They identified levers and hurdles based on the current development trends. The outcomes from their study do not claim identified connections as "causal" but rather a methodological attempt in approaching causality. Based on statistical analysis and expert assessment, they applied systems modelling to explore the influence of levers and hurdles in achieving the SDGs. In our analysis, we used their SDG interaction data to compare the casual linkages identified by the DAF.

Different Impact Type and Levels of Evidence are incorporated in the DAF to help integrate multifaceted information and for adjusting potential biases, which may arise because of fragmented evidence and knowledge gaps in the literature. Level of Evidence 1 supports capturing the opinions to incorporate logical relations if the user believes it to be true. In Level 2, the user is expected to go further from their hypothesis in Level 1 with more concrete evidence, which may exist but are fragmented in literature. These first two Levels of Evidence guide the user first to integrate their hypothesis in the DAF, which can act as a precursor for the successive iterations. The DAF encourages the users to eventually fill the evidence at Level 3 so that the final outcome is less subjective and well-grounded in scientific evidence, where possible. In the cases where the user finds it challenging to reach Level of Evidence 3, the knowledge at Level 1 and Level 2 might act as gap identifiers, evidencing the need to further research for sustainable development through novel science-based methodologies with complexities across contexts and actors [117]. Proper grounding in reality with evidence will also ensure that the DAF outcomes are usable or doable, meaning that the intervention, actors, and context necessary for identifying impacts are explicitly identified for aligning the DIs for sustainable development [118]. As reflected in Section 3, the DAF can also be designated as an iterative process, intended to be an evolving tool, with a set of evidence-backed theories relevant to a specific context that could be articulated, tested, and improved over time [74]. In this sense, the DAF supports in realizing the impacts not only by initial articulation but also as a lesson for long-term planning and practices. The DAF can also aid in understanding whether the new DIs can be transferred across the regions, especially taking into consideration the diverse requirements of each region's development processes. 
The test case studies discussed in this paper showcase how the DAF helps identify potential risks, unintended consequences, and identification of potential missed opportunities by using digitalization. The framework presents an integrative approach along with the evidence-based one since both are crucial because finding concrete evidence for all the potential long and short-term impacts related to the DIs across all the indicators of SDGs is challenging. As can be identified from 3 different test case studies, the DAF also helps expand the sectorial and isolated goal level approaches existing in literature (Gupta et al. [8], Vinuesa et al. [12]) by recognizing the DI's role in a certain context and the overarching effects on the SDG framework as a whole. The DAF also supports factoring in the indirect and uncertain impacts of the DIs for SDGs, which could help avoid uncritical optimism or systematic pessimism by accounting for all the indicators of SDGs while reiterating the DAF in different phases grounded in a particular context. Anticipating the role of the DI in context also supports comprehending that technological intervention is just part of a more extensive configuration and utilizing that may have closely tied trade-offs to other SDGs indicators and beyond, encouraging mindfulness. The DAF is designed to be improved further in future work with other actors as applied to various DIs.

The impact profile generated by filling potential impacts on all the SDG indicators for the 3 test case studies suggests that each of them have some aspect aligned in synergy (in Green), whereas some are not yet known to be aligned (in Yellow, Grey, and Blue) and some are trade-offs in their alignment (in Red). These colorful contrasting impacts suggest the need to balance them for sustainable development. The DAF supports revealing these contrasting impacts more systematically. Impact profiles of the three distinct DIs also provide fine-grained insights about diverse impacts on some SDGs over others. Test case 1 impact profile highlight more trade-offs for SDG 7 and 8, whereas in test case 2, the trade-offs increased for more SDGs such as in 9,11,12, and 13, and in test case 3, the trade-offs are approximately close to the test case 2 but the increased synergies compared to test case 2 with a higher level of evidence reflect the balancing impact. Although the contexts for the three case studies and their purposes are different, the comparison above reflects the benefit the DAF provides to uncover these complex and diverse effects that need to be regarded for sustainable development.

Overall, the DAF makes it possible to systematically gather the fragmented scientific knowledge using the practical theories and knowledge to assess the vital gaps and collaborations required for fostering Agenda 2030 and beyond. For example, considering test case 2, we were able to identify potential trade-offs in Indicator 4.2.2, which could lead to a social divide; however, if utilized mindfully in collaboration with partners fostering digital learning, the trade-offs can serve as synergy and could support in the progress of many other indicators from Goal 3,1 and 11 by encouraging participation and inclusiveness. We want to highlight that the DAF also helps identify aspects that are not covered by the SDG indicator (see, e.g., test cases 1 and 3 about privacy and cybersecurity), which may hint where a possible Post-2030 Agenda might need to be extended. Some of the findings in the test cases have already been well known. For example, the recent studies prove how the DI paradigms, predominantly Big Data and Artificial Intelligence, are crucial for advancing the progress of SDGs $[12,119,120]$. However, the DAF makes it possible to systematically use the fragmented scientific literature, identify the crucial gaps and observe potential collaborations required for fostering Agenda 2030 and beyond, comprehending tensions across space and time. Digitalization should be mindfully harnessed to monitor and achieve progress, then augment and scale up for releasing the full potential for sustainable development. Given the exceptional prospects that digitalization brings for progressing SDGs, the DAF serves as a novel analytical tool to explore the role of the DIs by facilitating further assessments, supporting to cope with uncertainties, and context inclusive systemic actions.

Finally, we remark that the context and the stakeholder structures can be explored in more detail than we did in the three test case studies, which was not a primary goal of this research. This paper aims to provide a thorough description of the principles of the DAF and its significance for the digitainability assessment. Future work could also incorporate diverse actors and target groups, particularly those 
with contrasting contexts and interventions, to further knowledge generation towards inclusive action for sustainability.

\section{Conclusion and Outlook}

The goal of the DAF introduced in this article is to provide a systematic assessment of the impacts and potential, but also possible trade-offs of digitalization on sustainable development (the "digitainability"). The DAF should make it possible to provide a common umbrella for various partial and sectorial approaches in the literature by relating the analysis to the widely accepted SDG indicator framework. The DAF serves as a starting point for realizing the mindful choices considering the synergy, trade-offs, and critical aspects of the DIs for SDGs as a whole. The context-inclusive nature of the framework helps assess the impacts the DIs offers for SDGs at the indicator level considering local to global contemplation, assisting in a more targeted analysis of the impact DIs may have on critical interlinkages of SDGs. The framework supports the step-by-step impact assessment of the DI across all SDG indicators and beyond, fostering evaluation across a broad spectrum of aspects such as ethics, environment, economy, and society in the digital age. Considering the emerging discussions on sustainability in the digital age, the outcome of the present study serves as an important means for key stakeholders to mindfully articulate, collaborate, and deliver the systems change required to harness the opportunities offered by digitalization for sustainable development. It offers stakeholders a strategic tool for spotting the potential opportunities and risks while maintaining its responsibility for sustainable development. The integration of practical insights with a theoretical outlook helps predict the future, which is not accurate science. The DAF could help in identifying potential pathways through the complex digitalization-sustainability practices. The framework also helps identify traits that are not covered by the current indicator framework of Agenda 2030 for enriching the discussion about the mindful use of digitalization for future sustainable development in the digital age. Beyond that, to enhance the perceived link between digitalization and sustainable development, the DAF guides in gathering crucial scientific pieces of evidence about how various actors and stakeholders can undertake effort mindfully. Altogether, the DAF helps in identifying the gaps and asking the right question, pinpointing potential impacts digitalization may have to shape the future more sustainably.

Future work will focus on automating some of the DAF procedures with the help of machine learning approaches, including topic-modeling and automatic text extraction, that have helped investigate the critical topics in a set of documents, such as articles published in academic journals, political texts, and in data-driven journalism [121,122]. Automating the topic extraction process in the future might support decreasing subjectivity biases and enhance re-iteration of the evidence analysis. In the long run, particularly in a context where literature on the DIs for SDGs is growing, the automated process might allow assessing key considerations and criteria from diverse domains simultaneously. However, it will be important to consider that the automated processes should be grounded in the context of the intervention and the role of the actors in the process. The scope of the DAF presented in this paper is to stimulate the assessment of the impact of DI on sustainable development, devising methodological agenda dedicated to evaluating the technical improvements required in the DI for being aligned with SDG indicators. Future empirical studies could utilize approaches such as design science research methodology [59] for going a step ahead and developing systematic evaluation frameworks for the improvement of DIs. The problem-solving paradigm of design science research inculcates the application key critical dimensions discussed in this paper, such as context and stakeholders within design theories, to realize the innovative artifacts for addressing real-world problems [123], offering guidelines for evaluation and iteration for improvement in the DI systems for sustainable development.

Acknowledgments: The authors gratefully acknowledge funding provided by the German Federal Ministry for Education and Research (BMBF) for the project "digitainable".

Author Contributions: SG conceptualization, developed methodology, performed formal analysis, investigated, prepared written—original draft. SG and JR reviewed \& edited the draft along with essential feedback. 
Conflicts of Interest: The authors declare no conflict of interest.

\section{References}

1. United Nations Department of Economic and Social Affairs. Transforming our world: The 2030 agenda for Sustainable Development 2015.

2. Chakraborty, C. Artificial intelligence and the fourth industrial revolution; Jenny Stanford Publishing, 2021.

3. Tegmark, M. Life 3.0: Being human in the age of artificial intelligence; Knopf, 2017.

4. Katz, R.L.; Koutroumpis, P. Measuring digitization: A growth and welfare multiplier. Technovation 2013, 33, 314-319.

5. Vial, G. Understanding digital transformation: A review and a research agenda. The journal of strategic information systems 2019, 28, 118-144.

6. Verhoef, P.C.; Broekhuizen, T.; Bart, Y.; Bhattacharya, A.; Dong, J.Q.; Fabian, N.; Haenlein, M. Digital transformation: A multidisciplinary reflection and research agenda. Journal of Business Research 2021, 122, 889-901.

7. Van der Velden, M. Digitalisation and the UN Sustainable Development Goals: What role for design. IDEA Interaction design $\mathcal{E}$ architecture (s) 2018, pp. 160-174.

8. Gupta, S.; Motlagh, M.; Rhyner, J. The digitalization sustainability matrix: A participatory research tool for investigating digitainability. Sustainability 2020, 12, 9283.

9. Goralski, M.A.; Tan, T.K. Artificial intelligence and sustainable development. The International Journal of Management Education 2020, 18, 100330.

10. Zhao, Z.; Cai, M.; Wang, F.; Winkler, J.A.; Connor, T.; Chung, M.G.; Zhang, J.; Yang, H.; Xu, Z.; Tang, Y.; others. Synergies and tradeoffs among Sustainable Development Goals across boundaries in a metacoupled world. Science of the Total Environment 2021, 751, 141749.

11. van Wynsberghe, A. Sustainable AI: AI for sustainability and the sustainability of AI. AI and Ethics 2021, pp. 1-6.

12. Vinuesa, R.; Azizpour, H.; Leite, I.; Balaam, M.; Dignum, V.; Domisch, S.; Felländer, A.; Langhans, S.D.; Tegmark, M.; Nerini, F.F. The role of artificial intelligence in achieving the Sustainable Development Goals. Nature communications 2020, 11, 1-10.

13. Kuntsman, A.; Rattle, I. Towards a paradigmatic shift in sustainability studies: a systematic review of peer reviewed literature and future agenda setting to consider environmental (Un) sustainability of digital communication. Environmental Communication 2019, 13, 567-581.

14. Yoon, B.; Shin, J.; Lee, S. Technology assessment model for sustainable development of LNG terminals. Journal of Cleaner Production 2018, 172, 927-937.

15. Andries, A.; Morse, S.; Murphy, R.; Lynch, J.; Woolliams, E.; Fonweban, J. Translation of Earth observation data into sustainable development indicators: An analytical framework. Sustainable Development 2019, 27, 366-376.

16. United Nations Department of Economic and Social Affairs. Global indicator framework for the Sustainable Development Goals and targets of the 2030 Agenda for Sustainable Development. https:/ / unstats.un.org/ sdgs/indicators/Global\%20Indicator\%20Framework\%20after\%202021\%20refinement_Eng.pdf. Accessed: 2021-09-01.

17. Sacco, P.; Gargano, E.R.; Cornella, A. Sustainable digitalization: a systematic literature review to identify how to make digitalization more sustainable. International TRIZ Future Conference. Springer, 2021, pp. 14-29.

18. Pappas, I.O.; Mikalef, P.; Giannakos, M.N.; Krogstie, J.; Lekakos, G. Big data and business analytics ecosystems: paving the way towards digital transformation and sustainable societies, 2018.

19. E-Participation Index. https://publicadministration.un.org/egovkb/en-us/About/Overview/EParticipation-Index. Accessed: 2021-06-01.

20. Kostoska, O.; Kocarev, L. A novel ICT framework for sustainable development goals. Sustainability 2019, $11,1961$.

21. Chalmers, G. The SDG Impact Assessment Tool-a free online tool for self-assessments of impacts on Agenda 2030. Policy 2019, 1, 150-167. 
22. Cowls, J.; Tsamados, A.; Taddeo, M.; Floridi, L. A definition, benchmark and database of AI for social good initiatives. Nature Machine Intelligence 2021, 3, 111-115.

23. del Río Castro, G.; Fernández, M.C.G.; Colsa, Á.U. Unleashing the convergence amid digitalization and sustainability towards pursuing the Sustainable Development Goals (SDGs): A holistic review. Journal of Cleaner Production 2020, p. 122204.

24. Lu, Y.; Nakicenovic, N.; Visbeck, M.; Stevance, A.S. Policy: five priorities for the UN sustainable development goals. Nature News 2015, 520, 432.

25. Schmidt, H.; Gostin, L.O.; Emanuel, E.J. Public health, universal health coverage, and Sustainable Development Goals: can they coexist? The Lancet 2015, 386, 928-930.

26. Adshead, D.; Thacker, S.; Fuldauer, L.I.; Hall, J.W. Delivering on the Sustainable Development Goals through long-term infrastructure planning. Global Environmental Change 2019, 59, 101975.

27. Schroeder, P.; Anggraeni, K.; Weber, U. The relevance of circular economy practices to the sustainable development goals. Journal of Industrial Ecology 2019, 23, 77-95.

28. Khalili, N.R.; Cheng, W.; McWilliams, A. A methodological approach for the design of sustainability initiatives: in pursuit of sustainable transition in China. Sustainability Science 2017, 12, 933-956.

29. Collste, D.; Pedercini, M.; Cornell, S.E. Policy coherence to achieve the SDGs: using integrated simulation models to assess effective policies. Sustainability science 2017, 12, 921-931.

30. Nerini, F.F.; Tomei, J.; To, L.S.; Bisaga, I.; Parikh, P.; Black, M.; Borrion, A.; Spataru, C.; Broto, V.C.; Anandarajah, G.; others. Mapping synergies and trade-offs between energy and the Sustainable Development Goals. Nature Energy 2018, 3, 10-15.

31. Velis, M.; Conti, K.I.; Biermann, F. Groundwater and human development: synergies and trade-offs within the context of the sustainable development goals. Sustainability science 2017, 12, 1007-1017.

32. Bisaga, I.; Parikh, P.; Tomei, J.; To, L.S. Mapping synergies and trade-offs between energy and the sustainable development goals: A case study of off-grid solar energy in Rwanda. Energy Policy 2021, 149, 112028.

33. Singh, G.G.; Cisneros-Montemayor, A.M.; Swartz, W.; Cheung, W.; Guy, J.A.; Kenny, T.A.; McOwen, C.J.; Asch, R.; Geffert, J.L.; Wabnitz, C.C.; others. A rapid assessment of co-benefits and trade-offs among Sustainable Development Goals. Marine Policy 2018, 93, 223-231.

34. Pradhan, P.; Costa, L.; Rybski, D.; Lucht, W.; Kropp, J.P. A systematic study of sustainable development goal (SDG) interactions. Earth's Future 2017, 5, 1169-1179.

35. Scherer, L.; Behrens, P.; de Koning, A.; Heijungs, R.; Sprecher, B.; Tukker, A. Trade-offs between social and environmental Sustainable Development Goals. Environmental science E policy 2018, 90, 65-72.

36. Mainali, B.; Luukkanen, J.; Silveira, S.; Kaivo-Oja, J. Evaluating synergies and trade-offs among Sustainable Development Goals (SDGs): Explorative analyses of development paths in South Asia and Sub-Saharan Africa. Sustainability 2018, 10, 815.

37. von Stechow, C.; Minx, J.C.; Riahi, K.; Jewell, J.; McCollum, D.L.; Callaghan, M.W.; Bertram, C.; Luderer, G.; Baiocchi, G. $2^{\circ} \mathrm{C}$ and SDGs: united they stand, divided they fall? Environmental Research Letters 2016, $11,034022$.

38. Sorrell, S. Jevons' Paradox revisited: The evidence for backfire from improved energy efficiency. Energy policy 2009, 37, 1456-1469.

39. Nishant, R.; Teo, T.S.; Goh, M. Energy efficiency benefits: is technophilic optimism justified? IEEE Transactions on Engineering Management 2014, 61, 476-487.

40. Hidalgo, A.; Gabaly, S.; Morales-Alonso, G.; Urueña, A. The digital divide in light of sustainable development: An approach through advanced machine learning techniques. Technological Forecasting and Social Change 2020, 150, 119754.

41. Kopnina, H. Education for the future? Critical evaluation of education for sustainable development goals. The Journal of Environmental Education 2020, 51, 280-291.

42. Sanchez, D.O.M. Sustainable Development Challenges and Risks of Industry 4.0: A literature review. 2019 Global IoT Summit (GIoTS). IEEE, 2019, pp. 1-6.

43. Dawes, J.H. Are the Sustainable Development Goals self-consistent and mutually achievable? Sustainable Development 2020, 28, 101-117.

44. Fukuda-Parr, S.; McNeill, D. Knowledge and Politics in Setting and Measuring the SDGs, Special Issue of Global Policy 2019, 2019. 
45. Letouzé, E.; Pentland, A. Towards a human artificial intelligence for human development. ITU Journal: ICT Discoveries 2018.

46. Weitz, N.; Carlsen, H.; Nilsson, M.; Skånberg, K. Towards systemic and contextual priority setting for implementing the 2030 Agenda. Sustainability science 2018, 13, 531-548.

47. Tsamados, A.; Aggarwal, N.; Cowls, J.; Morley, J.; Roberts, H.; Taddeo, M.; Floridi, L. The ethics of algorithms: key problems and solutions. AI E SOCIETY 2021, pp. 1-16.

48. Breuer, A.; Janetschek, H.; Malerba, D. Translating sustainable development goal (SDG) interdependencies into policy advice. Sustainability 2019, 11, 2092.

49. Kroll, C.; Warchold, A.; Pradhan, P. Sustainable Development Goals (SDGs): Are we successful in turning trade-offs into synergies? Palgrave Communications 2019, 5, 1-11.

50. Schneider, F.; Kläy, A.; Zimmermann, A.B.; Buser, T.; Ingalls, M.; Messerli, P. How can science support the 2030 Agenda for Sustainable Development? Four tasks to tackle the normative dimension of sustainability. Sustainability Science 2019, 14, 1593-1604.

51. Edwards, N.; Barker, P.M. The importance of context in implementation research. JAIDS Journal of Acquired Immune Deficiency Syndromes 2014, 67, S157-S162.

52. May, C.R.; Johnson, M.; Finch, T. Implementation, context and complexity. Implementation Science 2016, 11, 1-12.

53. Nilsen, P. Making sense of implementation theories, models, and frameworks. In Implementation Science 3.0; Springer, 2020; pp. 53-79.

54. Gabora, L.; Aerts, D. Evolution as context-driven actualisation of potential: toward an interdisciplinary theory of change of state. Interdisciplinary Science Reviews 2005, 30, 69-88.

55. Tamilmani, K.; Rana, N.P.; Wamba, S.F.; Dwivedi, R. The extended Unified Theory of Acceptance and Use of Technology (UTAUT2): A systematic literature review and theory evaluation. International Journal of Information Management 2021, 57, 102269.

56. Pfadenhauer, L.M.; Gerhardus, A.; Mozygemba, K.; Lysdahl, K.B.; Booth, A.; Hofmann, B.; Wahlster, P.; Polus, S.; Burns, J.; Brereton, L.; others. Making sense of complexity in context and implementation: the Context and Implementation of Complex Interventions (CICI) framework. Implementation science 2017, 12, 1-17.

57. Dang, H.A.H.; Serajuddin, U. Tracking the sustainable development goals: Emerging measurement challenges and further reflections; The World Bank, 2019.

58. Barbier, E.B.; Burgess, J.C. Sustainable development goal indicators: Analyzing trade-offs and complementarities. World development 2019, 122, 295-305.

59. vom Brocke, J.; Hevner, A.; Maedche, A. Introduction to Design Science Research. In Design Science Research. Cases; Springer, 2020; pp. 1-13.

60. Grainger-Brown, J.; Malekpour, S. Implementing the sustainable development goals: A review of strategic tools and frameworks available to organisations. Sustainability 2019, 11, 1381.

61. Laurian, L.; Walker, M.; Crawford, J. Implementing environmental sustainability in local government: The impacts of framing, agency culture, and structure in US cities and counties. International Journal of Public Administration 2017, 40, 270-283.

62. Krellenberg, K.; Bergsträßer, H.; Bykova, D.; Kress, N.; Tyndall, K. Urban sustainability strategies guided by the SDGs-A tale of four cities. Sustainability 2019, 11, 1116.

63. Köhler, J.; Geels, F.W.; Kern, F.; Markard, J.; Onsongo, E.; Wieczorek, A.; Alkemade, F.; Avelino, F.; Bergek, A.; Boons, F.; others. An agenda for sustainability transitions research: State of the art and future directions. Environmental Innovation and Societal Transitions 2019, 31, 1-32.

64. Walsh, P.P.; Murphy, E.; Horan, D. The role of science, technology and innovation in the UN 2030 agenda. Technological Forecasting and Social Change 2020, 154, 119957.

65. Senit, C.A. Leaving no one behind? The influence of civil society participation on the Sustainable Development Goals. Environment and Planning C: Politics and Space 2020, 38, 693-712.

66. Guan, T.; Meng, K.; Liu, W.; Xue, L. Public attitudes toward sustainable development goals: Evidence from five Chinese cities. Sustainability 2019, 11, 5793.

67. Messerli, P.; Kim, E.M.; Lutz, W.; Moatti, J.P.; Richardson, K.; Saidam, M.; Smith, D.; Eloundou-Enyegue, P.; Foli, E.; Glassman, A.; others. Expansion of sustainability science needed for the SDGs. Nature sustainability 2019, 2, 892-894. 
68. Dalby, S.; Horton, S.; Mahon, R.; Thomaz, D. Achieving the sustainable development goals: global governance challenges; Routledge, 2019.

69. Kurz, R. UN SDGs: disruptive for companies and for universities? In The Future of the UN Sustainable Development Goals; Springer, 2020; pp. 279-290.

70. Bergman, Z.; Bergman, M.M.; Fernandes, K.; Grossrieder, D.; Schneider, L. The contribution of UNESCO chairs toward achieving the UN sustainable development goals. Sustainability 2018, 10, 4471.

71. Lopez, B. Connecting business and sustainable development goals in Spain. Marketing Intelligence $\mathcal{E}$ Planning 2020.

72. Pimonenko, T.; Bilan, Y.; Horák, J.; Starchenko, L.; Gajda, W. Green brand of companies and greenwashing under sustainable development goals. Sustainability 2020, 12, 1679.

73. Allen, W.; Cruz, J.; Warburton, B. How decision support systems can benefit from a theory of change approach. Environmental management 2017, 59, 956-965.

74. Anderson, A.A. The community builder's approach to Theory of Change 2006.

75. James, C. Theory of change review. Comic Relief 2011.

76. Bonell, C.; Melendez-Torres, G.; Viner, R.M.; Rogers, M.B.; Whitworth, M.; Rutter, H.; Rubin, G.J.; Patton, G. An evidence-based theory of change for reducing SARS-CoV-2 transmission in reopened schools. Health $\mathcal{E}$ place 2020, p. 102398.

77. Mayne, J. Sustainability Analysis of Intervention Benefits: A Theory of Change Approach. Canadian Journal of Program Evaluation 2020, 35.

78. Li, Y.; Thomas, M.A. Adopting a theory of change approach for ict4d project impact assessment-the case of cmes project. International Conference on Social Implications of Computers in Developing Countries. Springer, 2019, pp. 95-109.

79. Taplin, D.H.; Clark, H. Theory of change basics: A primer on theory of change. New York NY: ActKnowledge 2012.

80. Stein, D.; Valters, C. Understanding theory of change in international development 2012.

81. Van Stolk, C.; Ling, T.; Reding, A.; Bassford, M. Monitoring and evaluation in stabilisation interventions 2011.

82. Valters, C. Theories of change in international development: Communication, learning, or accountability. JSRP Paper 2014, 17.

83. Cowls, J.; Tsamados, A.; Taddeo, M.; Floridi, L. The AI Gambit_Leveraging artificial intelligence to combat climate change: Opportunities, challenges, and recommendations. Challenges, and Recommendations (March 15, 2021) 2021.

84. WHO. WHO releases country estimates on air pollution exposure and health impact 2016.

85. Travaglio, M.; Yu, Y.; Popovic, R.; Selley, L.; Leal, N.S.; Martins, L.M. Links between air pollution and COVID-19 in England. Environmental Pollution 2021, 268, 115859.

86. Fattorini, D.; Regoli, F. Role of the chronic air pollution levels in the Covid-19 outbreak risk in Italy. Environmental Pollution 2020, 264, 114732.

87. Jiao, W.; Hagler, G.; Williams, R.; Sharpe, R.; Brown, R.; Garver, D.; Judge, R.; Caudill, M.; Rickard, J.; Davis, M.; others. Community Air Sensor Network (CAIRSENSE) project: evaluation of low-cost sensor performance in a suburban environment in the southeastern United States. Atmospheric Measurement Techniques 2016, 9, 5281-5292.

88. Gupta, S.; Pebesma, E.; Degbelo, A.; Costa, A.C. Optimising Citizen-Driven Air Quality Monitoring Networks for Cities. ISPRS International Journal of Geo-Information 2018, 7, 468.

89. Chen, F.; Chen, Z. Cost of economic growth: Air pollution and health expenditure. Science of The Total Environment 2021, 755, 142543.

90. Owili, P.O.; Lien, W.H.; Muga, M.A.; Lin, T.H. The associations between types of ambient PM2. 5 and under-five and maternal mortality in Africa. International journal of environmental research and public health 2017, 14, 359.

91. Popovic, I.; Magalhaes, R.J.S.; Ge, E.; Marks, G.B.; Dong, G.H.; Wei, X.; Knibbs, L.D. A systematic literature review and critical appraisal of epidemiological studies on outdoor air pollution and tuberculosis outcomes. Environmental research 2019, 170, 33-45.

92. Rajagopalan, S.; Al-Kindi, S.G.; Brook, R.D. Air pollution and cardiovascular disease: JACC state-of-the-art review. Journal of the American College of Cardiology 2018, 72, 2054-2070. 
93. Liang, L.; Cai, Y.; Barratt, B.; Lyu, B.; Chan, Q.; Hansell, A.L.; Xie, W.; Zhang, D.; Kelly, F.J.; Tong, Z. Associations between daily air quality and hospitalisations for acute exacerbation of chronic obstructive pulmonary disease in Beijing, 2013-17: an ecological analysis. The Lancet Planetary Health 2019, 3, e270-e279.

94. Nissilä, J.J.; Savelieva, K.; Lampi, J.; Ung-Lanki, S.; Elovainio, M.; Pekkanen, J. Parental worry about indoor air quality and student symptom reporting in primary schools with or without indoor air quality problems. Indoor Air 2019, 29, 865-873.

95. Casazza, M.; Maraga, F.; Liu, G.; Lega, M.; Turconi, L.; Ulgiati, S. River water quality and its relation with air quality: a long-term case study in a remote and pristine NW Italian headwater catchment. Journal of Environmental Accounting and Management 2017, 5, 35-47.

96. Camprodon, G.; González, Ó.; Barberán, V.; Pérez, M.; Smári, V.; de Heras, M.Á.; Bizzotto, A. Smart Citizen Kit and Station: An open environmental monitoring system for citizen participation and scientific experimentation. HardwareX 2019, 6, e00070.

97. Misic, J.; Misic, V.B.; Banaie, F. Reliable and scalable data acquisition from IoT domains. GLOBECOM 2017-2017 IEEE Global Communications Conference. IEEE, 2017, pp. 1-6.

98. Tu, M.; Chung, W.H.; Chiu, C.K.; Chung, W.; Tzeng, Y. A novel IoT-based dynamic carbon footprint approach to reducing uncertainties in carbon footprint assessment of a solar PV supply chain. 2017 4th International Conference on Industrial Engineering and Applications (ICIEA). IEEE, 2017, pp. 249-254.

99. Chamola, V.; Hassija, V.; Gupta, V.; Guizani, M. A comprehensive review of the COVID-19 pandemic and the role of IoT, drones, AI, blockchain, and 5G in managing its impact. Ieee access 2020, 8, 90225-90265.

100. Jin, Z.; Chen, Y. Telemedicine in the cloud era: Prospects and challenges. IEEE Pervasive Computing 2015, 14, 54-61.

101. Ekeland, A.G.; Bowes, A.; Flottorp, S. Effectiveness of telemedicine: a systematic review of reviews. International journal of medical informatics 2010, 79, 736-771.

102. Margheri, A.; Masi, M.; Miladi, A.; Sassone, V.; Rosenzweig, J. Decentralised provenance for healthcare data. International Journal of Medical Informatics 2020, 141, 104197.

103. SERIES, B.P. Opportunities and Challenges of Blockchain Technologies in Health Care 2020.

104. Musabi, A.G.; Thiga, M.M.; Karume, S.M. Enabling Secure Maternal Health Information Exchange using Blockchain.

105. Resiere, D.; Resiere, D.; Kallel, H. Implementation of medical and scientific cooperation in the Caribbean using blockchain technology in coronavirus (Covid-19) pandemics. Journal of medical systems 2020, 44, 1-2.

106. Krittanawong, C.; Rogers, A.J.; Aydar, M.; Choi, E.; Johnson, K.W.; Wang, Z.; Narayan, S.M. Integrating blockchain technology with artificial intelligence for cardiovascular medicine. Nature Reviews Cardiology 2020, 17, 1-3.

107. Bell, L.; Buchanan, W.J.; Cameron, J.; Lo, O. Applications of blockchain within healthcare. Blockchain in healthcare today 2018.

108. Sedlmeir, J.; Buhl, H.U.; Fridgen, G.; Keller, R. The energy consumption of blockchain technology: beyond myth. Business \& Information Systems Engineering 2020, 62, 599-608.

109. Stoll, C.; Klaaßen, L.; Gallersdörfer, U. The carbon footprint of bitcoin. Joule 2019, 3, 1647-1661.

110. Mainelli, M. Blockchain will help us prove our identities in a digital world. Blockchain: The Insights You Need From Harvard Business Review (HBR Insights Series) 2017.

111. Deparday, V.; Gevaert, C.M.; Molinario, G.; Soden, R.; Balog-Way, S. Machine learning for disaster risk management 2019.

112. Biffis, E.; Chavez, E. Satellite data and machine learning for weather risk management and food security. Risk Analysis 2017, 37, 1508-1521.

113. Tatar, N.; Saadatseresht, M.; Arefi, H.; Hadavand, A. A robust object-based shadow detection method for cloud-free high resolution satellite images over urban areas and water bodies. Advances in Space Research 2018, 61, 2787-2800.

114. Santos, L.B.L.; Londe, L.R.; de Carvalho, T.J.; Menasché, D.S.; Vega-Oliveros, D.A. About interfaces between machine learning, complex networks, survivability analysis, and disaster risk reduction. In Towards Mathematics, Computers and Environment: A Disasters Perspective; Springer, 2019; pp. 185-215.

115. García-Martín, E.; Rodrigues, C.F.; Riley, G.; Grahn, H. Estimation of energy consumption in machine learning. Journal of Parallel and Distributed Computing 2019, 134, 75-88. 
116. Anderson, C.C.; Denich, M.; Warchold, A.; Kropp, J.P.; Pradhan, P. A systems model of SDG target influence on the 2030 Agenda for Sustainable Development. Sustainability science 2021, pp. 1-14.

117. Sachs, J.D.; Schmidt-Traub, G.; Mazzucato, M.; Messner, D.; Nakicenovic, N.; Rockström, J. Six transformations to achieve the sustainable development goals. Nature Sustainability 2019, 2, 805-814.

118. Bester, A. Results-based management in the United Nations Development System: progress and challenges. A report prepared for the United Nations Department of Economic and Social Affairs, for the Quadrennial Comprehensive Policy Review 2012, 2730.

119. Initiative, G.E.S.; others. Digital with Purpose, 2019.

120. Malhotra, C.; Anand, R.; Singh, S. Applying big data analytics in governance to achieve sustainable development goals (SDGs) in India. In Data Science Landscape; Springer, 2018; pp. 273-291.

121. Mustak, M.; Salminen, J.; Plé, L.; Wirtz, J. Artificial intelligence in marketing: Topic modeling, scientometric analysis, and research agenda. Journal of Business Research 2021, 124, 389-404.

122. Sekiya, T.; Matsuda, Y.; Yamaguchi, K. Analysis of computer science related curriculum on LDA and Isomap. Proceedings of the fifteenth annual conference on Innovation and technology in computer science education, 2010, pp. 48-52.

123. Apiola, M.; Sutinen, E. Design science research for learning software engineering and computational thinking: Four cases. Computer Applications in Engineering Education 2021, 29, 83-101. 
944 (C) 2022 by the authors. Submitted to Sustainability for possible open access publication 945 under the terms and conditions of the Creative Commons Attribution (CC BY) license 946 (http://creativecommons.org/licenses/by/4.0/). 